\title{
Níveis de Energia Metabolizável para Frangos de Corte no Período de 22 a 42 Dias de Idade Mantidos em Ambiente Termoneutro ${ }^{1}$
}

\author{
Adhemar Rodrigues de Oliveira Neto², Rita Flávia Miranda de Oliveira3 ${ }^{3}$, Juarez Lopes Donzele ${ }^{3}$, \\ Horacio Santiago Rostagno ${ }^{3}$, Rony Antonio Ferreira ${ }^{2}$, Humberto Maximiano do Carmo 4
}

\begin{abstract}
RESUMO - Este experimento foi realizado para avaliar os efeitos de níveis de energia metabolizável (EM) da ração sobre desempenho, qualidade de carcaça e variáveis fisiológicas de frangos de corte dos 22 aos 42 dias de idade mantidos em ambiente de termoneutralidade $\left(23,2 \pm 0,74^{\circ} \mathrm{C}\right)$. Foram utilizados 240 frangos de corte machos Hubbard, com peso médio inicial de $753 \pm 3,03 \mathrm{~g}$, em delineamento inteiramente casualizado com cinco tratamentos (3000, 3075, 3150, 3225 e 3300 kcal de energia metabolizável/kg de ração), seis repetições e oito aves por unidade experimental. As rações experimentais isoprotéicas foram fornecidas às aves de forma controlada, correspondente a $95 \%$ do consumo voluntário, para que o consumo de proteína fosse igual em todos os tratamentos. O ganho de peso, o consumo de EM, a conversão alimentar e as deposições de proteína e gordura na carcaça melhoraram linearmente com o aumento do nível de EM da ração, enquanto o rendimento de carcaça diminuiu de forma linear com o nível de EM. Não foi verificado efeito do nível de EM das rações sobre os pesos absoluto e relativo de coxas, sobrecoxas, pernas e peito com osso e sem osso, coração, fígado, moela proventrículo, pulmões, intestino, gordura abdominal e penas. Não se observou efeito do nível de EM da ração sobre a concentração sérica de triiodotironina livre. O nível de 3232 kcal de EM, correspondente à relação energia:proteína calculada de 16,49, proporcionou os melhores resultados de desempenho e deposição de proteína na carcaça dos frangos de corte mantidos em ambiente termoneutro.
\end{abstract}

Palavras-chave: energia metabolizável, frangos de corte, termoneutralidade

\section{Metabolizable Energy Level for Broilers from 22 to 42 Days of Age Maintained under Thermoneutral Environment}

\begin{abstract}
This experiment was conducted to evaluate the effects of metabolizable energy (ME) levels on performance, carcass quality and physiological traits of broilers from 22 to 42 days of age maintained under thermoneutral environment $\left(23.2 \pm 0.74{ }^{\circ} \mathrm{C}\right)$. Two hundred and forty Hubbard male broilers with average weight of $753 \pm 3.03 \mathrm{~g}$ were used in a completely randomized design with five treatments $(3000,3075,3150,3225$ and $3300 \mathrm{kcal}$ metabolizable energy $/ \mathrm{kg}$ diet $)$, six replicates and eight birds per experimental unit. The experimental isoproteic diets were fed to birds in a controlled way, corresponding to $95 \%$ of the voluntary intake, in order to maintain the same protein intake in all treatments. Weight gain, ME intake, feed:gain and fat and protein depositions linearly improved as dietary EM increased, with the carcass yield linearly reduced according to the ME levels. There was no effect of dietary ME level on absolute and relative weights of thigh, drumstick, legs, breast with bone, heart, liver, gizzard, proventriculus, lungs, intestine, abdominal fat and feathers. It was not observed the effect of the dietary ME level of the diet on the serum concentration of free triiodotironine. The level of $3232 \mathrm{kcal} \mathrm{ME}$, corresponding to the calculated energy:protein ratio of 16.49 , showed the best performance and protein deposition in the carcass of broilers maintained under thermoneutral environment.
\end{abstract}

Key Words: broilers, metabolizable energy, thermoneutral environment

\section{Introdução}

A energia que os animais obtêm dos alimentos é utilizada prioritariamente para a manutenção dos processos vitais, como respiração, manutenção da temperatura corporal e fluxo sangüíneo. A energia extra consumida pelos animais é depositada como tecido corporal. Contudo, durante a partição desta energia no organismo, ocorrem perdas que aparecem na forma de calor (incremento calórico), o qual, dependendo da condição ambiental, é utilizado para aquecer o corpo ou é dissipado para o ambiente.

Quando mantidos em ambiente termoneutro, os animais conseguem manter a homeotermia com o mínimo de esforço termorregulatório (CURTIS, 1983), sem gastos extras de energia, o que permite desempenho máximo.

Um animal mantido sob ambiente termoneutro

\footnotetext{
${ }^{1}$ Parte da Tese de Mestrado do primeiro autor - Projeto Financiado pela FAPEMIG.

${ }^{2}$ Estudante de Doutorado do DZO/UFV.

${ }^{3}$ Professor do DZO/UFV.

${ }^{4}$ Estudante de Zootecnia do DZO/UFV - Bolsista de Iniciação Científica - CNPq.
} 
consome alimento para satisfazer sua necessidade energética, conforme observado em estudos com aves (Fuller e Mora, 1973, citados por COFFEY et al., 1982). Segundo LEESSON et al. (1996), as aves com livre acesso ao alimento apresentam consumo de ração diminuído ou aumentado, em razão do alto ou baixo nível de energia metabolizável (EM), respectivamente, de modo que o consumo de energia não varia, mostrando eficiente controle das aves referente à ingestão de calorias. De acordo com esse autor, a utilização de rações com maiores níveis de EM melhora o ganho de peso e a conversão alimentar das aves.

Este trabalho foi realizado com o objetivo de avaliar o efeito de níveis de energia metabolizável (EM) sobre o desempenho de frangos de corte machos Hubbard, de 22 a 42 dias de idade, mantidos em ambiente termoneutro.

\section{Material e Métodos}

O experimento foi conduzido no Laboratório de Bioclimatologia Animal do Departamento de Zootecnia do Centro de Ciências Agrárias da Universidade Federal de Viçosa.

Foram utilizados 240 frangos de corte machos Hubbard com peso inicial médio de 753 $\pm 3,03 \mathrm{~g}$, no período de 22 a 42 dias de idade. O delineamento experimental utilizado foi o inteiramente casualizado com cinco tratamentos $(3000,3075,3150,3225$ e $3300 \mathrm{kcal}$ de EM/kg), seis repetições e oito aves por unidade experimental.

Durante o período inicial ( 1 a 21 dias de idade), as aves foram criadas em galpão convencional, recebendo ração com $3000 \mathrm{kcal}$ de EM/kg e 20,18\% de PB, para satisfazer suas exigências nutricionais, segundo ROSTAGNO et al. (1996) e manejadas conforme GOMES et al. (1996). Completados os 22 dias de idade, os frangos foram pesados e transferidos para as câmaras climáticas, quando teve início o período experimental. Os animais permaneceram no experimento até os 42 dias de idade.

As rações experimentais (Tabela 1), isoprotéicas, foram formuladas para satisfazerem às exigências de proteína, minerais e vitaminas de frangos de corte, de acordo com recomendações de ROSTAGNO et al. (1996). Os diferentes níveis de energia das rações (3000, 3075, 3150, 3225 e $3300 \mathrm{kcal}$ de EM/kg de ração) foram obtidos pela substituição do inerte (CAULIM) por óleo de soja.

As aves receberam ração controlada correspondente a $95 \%$ do consumo voluntário de aves mantidas na termoneutralidade, de forma que em todos os tratamentos as aves consumissem a mesma quantidade de proteína. Para determinação do consumo voluntário, utilizou-se um grupo adicional de 80 aves distribuídas em grupos de oito por compartimento, mantidas em câmara climática, sob as mesmas condições de conforto das aves do experimento, recebendo ração com $3150 \mathrm{kcal}$ de EM, atendendo à exigência das aves no período, segundo ROSTAGNO et al. (1996). A água foi fornecida à vontade nos bebedouros e trocada três vezes ao dia, para evitar o aquecimento.

Os frangos de corte foram alojados em grupos de oito, em compartimentos $(0,85 \times 0,85 \mathrm{~m})$ de baterias metálicas, providos de comedouro e bebedouro tipo calha, mantidos em salas climatizadas com temperatura e umidade relativa controladas. Cada compartimento constituiu uma unidade experimental.

As temperaturas e umidade relativas das salas foram registradas três vezes ao dia, por meio de termômetros de bulbo seco e úmido, de globo negro e de máxima e mínima, mantidos no centro da sala, representando o ambiente dos animais.

O programa de luz adotado foi o contínuo (24 horas de luz artificial), durante todo o período experimental, utilizando-se duas lâmpadas fluorescentes de 25 watts por sala.

As aves foram pesadas no início e no final do período experimental para determinação do ganho de peso. Da mesma forma, o consumo de ração foi calculado considerando-se a ração fornecida, os desperdícios e as sobras das rações nos comedouros, durante o período experimental. Posteriormente, calculou-se a conversão alimentar.

No 41으 dia, foi coletado sangue de duas aves por unidade experimental, após jejum de 3 horas ( 8 - 11 h), por meio de punção cardíaca. $O$ sangue coletado foi deixado em descanso à sombra por +1 h e 30 , sendo, posteriormente, centrifugado para retirada do soro, que foi imediatamente congelado, até o momento das dosagens do hormônio triiodotironina $\left(\mathrm{T}_{3}\right)$ livre.

No $42^{\circ}$ dia de idade, as aves foram pesadas após jejum alimentar de seis horas. Quatro aves em cada unidade experimental, com pesos mais próximos da média da respectiva unidade, foram abatidas. Após o sangramento e a depenação, as aves foram evisceradas e as carcaças (incluindo cabeça e pés) foram pesadas. Posteriormente, retirou-se e pesou-se a gordura abdominal.

Foram avaliados o peso absoluto $(\mathrm{g})$ e o rendimento (\%) das carcaças inteiras (com pés e cabeça), dos 
1134 Rev. bras. zootec.

Tabela 1 - Composição centesimal das rações experimentais

Table 1 - Percentage composition of the experimental diets

\begin{tabular}{|c|c|c|c|c|c|}
\hline \multirow[t]{2}{*}{$\begin{array}{l}\text { Ingrediente } \\
\text { Ingredient }\end{array}$} & \multicolumn{5}{|c|}{$\begin{array}{c}\text { Nível de energia metabolizável }(\mathrm{kcal} / \mathrm{kg}) \\
\text { Metabolizable energy level }(\mathrm{kcal} / \mathrm{kg})\end{array}$} \\
\hline & 3000 & 3075 & 3150 & 3225 & 3300 \\
\hline $\begin{array}{l}\text { Milho }(8,25 \% \mathrm{~PB})^{1} \\
\text { Corn grain }(8.25 \% \mathrm{CP})\end{array}$ & 56,00 & 56,00 & 56,00 & 56,00 & 56,00 \\
\hline $\begin{array}{l}\text { Farelo de soja }(45,97 \% \mathrm{~PB})^{1} \\
\text { Soybean meal }(45.97 \% \quad C P)\end{array}$ & 32,36 & 32,36 & 32,36 & 32,36 & 32,36 \\
\hline $\begin{array}{l}\text { Fosfato bicálcico } \\
\text { Dicalcium phosphate }\end{array}$ & 1,505 & 1,505 & 1,505 & 1,505 & 1,505 \\
\hline $\begin{array}{l}\text { Calcário } \\
\text { Limestone }\end{array}$ & 1,157 & 1,157 & 1,157 & 1,157 & 1,157 \\
\hline $\begin{array}{l}\text { Bacitracina de zinco }(10 \%) \\
\text { Zinz bacitracin }\end{array}$ & 0,020 & 0,020 & 0,020 & 0,020 & 0,020 \\
\hline $\begin{array}{l}\text { BHT (antioxidante) } \\
\text { BHT (antioxidant) }\end{array}$ & 0,020 & 0,020 & 0,020 & 0,020 & 0,020 \\
\hline $\begin{array}{l}\text { Cloreto de colina } \\
\text { Choline chlorate }\end{array}$ & 0,060 & 0,060 & 0,060 & 0,060 & 0,060 \\
\hline $\begin{array}{l}\text { Sal } \\
\text { Salt }\end{array}$ & 0,400 & 0,400 & 0,400 & 0,400 & 0,400 \\
\hline $\begin{array}{l}\text { Mistura vitamínica } \\
\text { Vitamin }^{2} x^{2}\end{array}$ & 0,100 & 0,100 & 0,100 & 0,100 & 0,100 \\
\hline $\begin{array}{l}\text { Mistura mineral } \\
\text { Mineral } \text { mix }^{3}\end{array}$ & 0,050 & 0,050 & 0,050 & 0,050 & 0,050 \\
\hline Dl-metionina & 0,195 & 0,195 & 0,195 & 0,195 & 0,195 \\
\hline Coban 200 (anticoccidiano) ${ }^{4}$ & 0,050 & 0,050 & 0,050 & 0,050 & 0,050 \\
\hline Óleo de soja & 3,860 & 4,710 & 5,565 & 6,410 & 7,270 \\
\hline $\begin{array}{l}\text { Soybean oil } \\
\text { Caulim }\end{array}$ & 4,233 & 3,373 & 2,518 & 1,673 & 0,813 \\
\hline $\begin{array}{l}\text { Composição calculada } \\
\text { Calculated composition }^{5} \\
\end{array}$ & & & & & \\
\hline $\begin{array}{l}\text { Energia metabolizável }(\mathrm{kcal} / \mathrm{kg}) \\
\text { Metabolizable energy }(\mathrm{kcal} / \mathrm{kg})\end{array}$ & 3000 & 3075 & 3150 & 3225 & 3300 \\
\hline $\begin{array}{l}\text { Proteína bruta }(\%) \\
\text { Crude protein }\end{array}$ & 19,60 & 19,60 & 19,60 & 19,60 & 19,60 \\
\hline $\begin{array}{l}\text { Lisina } \\
\text { Lysine }\end{array}$ & 1,058 & 1,058 & 1,058 & 1,058 & 1,058 \\
\hline $\mathrm{Ca}(\%)$ & 0,918 & 0,918 & 0,918 & 0,918 & 0,918 \\
\hline $\begin{array}{l}\text { P disponível (\%) } \\
\text { Available P }\end{array}$ & 0,387 & 0,387 & 0,387 & 0,387 & 0,387 \\
\hline $\begin{array}{l}\text { Sódio }(\%) \\
\text { Sodium }\end{array}$ & 0,200 & 0,200 & 0,200 & 0,200 & 0,200 \\
\hline $\begin{array}{l}1 \text { Valor analisado no Laboratório de Nu } \\
\text { por SILVA (1990) (Values obtained at } \\
2 \text { Premix vitamínico por kg de ração ( } V \\
\text { vit. E, } 15.000 \text { Ul; vit. } B_{1}, 2,0 \mathrm{~g} ; \text { vit. B } \\
\text { acid), } 25 \mathrm{~g} \text {; ácido pantotênico (pantoter } \\
\text { de zinco (zinc bacitracin), } 10 \mathrm{~g} ; \text { Se, } 250 \\
\text { vehicule), } 1000 \mathrm{~g} \text {. } \\
3 \text { Premix mineral por kg de ração (Mi } \\
\text { Co, } 2 \mathrm{~g} ; \mathrm{I}, 1 \mathrm{~g} \text {; e veículo q.s.p. (q.s.p } \\
4 \text { Monensina sódica, } 200 \mathrm{~g} / \mathrm{kg} \text { (Sodic } n \\
5 \text { Composição calculada segundo RO } \\
\text { Composition calcutated according to ROS }\end{array}$ & $\begin{array}{l}\text { animal do } \\
\text { nal Nutritior } \\
\text { nix per } \mathrm{kg} \text { of } \\
\text { g; vit. } \mathrm{B}_{6}, \\
10 \mathrm{~g} \text {; vit. } \\
\text { tioxidante } \\
\text { ix per } \mathrm{kg} \text { o } \\
\text { le), } 500 \mathrm{~g} . \\
\text { ne, } 200 \mathrm{~g} / \mathrm{k} \\
\mathrm{NO} \text { et al. } \\
\text { O et al. (19s }\end{array}$ & $\begin{array}{l}\text { O/UFV, d } \\
\text { aboratory o } \\
\text { t): vit. A, } 1 \\
\text { g; vit. B }{ }_{12} \\
\text { 3,0 g; ácic } \\
\text { IT (BHTan } \\
\text { et): Mn, } 6 \\
\text { 96), com }\end{array}$ & $\begin{array}{l}\text { Zcordo con } \\
Z O / U F V, \text { a } \\
\text { J00.000 U } \\
, 015 \mathrm{~g} \text {; ác } \\
\text { fólico (folic } \\
\text { xidant), } 10 \mathrm{c} \\
\text {; Fe, } 80 \\
\text { kceção da }\end{array}$ & $\begin{array}{l}\text { metodolog } \\
\text { ording to } S \\
\text { vit. } D_{3}, 1.5 \\
\text { lo nicotíni } \\
\text { sid), } 1,0 \mathrm{~g} ; \\
\text { e veículo } \\
\text { Zn, } 50 \mathrm{~g} \text {; } \\
\text { roteína br }\end{array}$ & $\begin{array}{l}\text { a descrita } \\
\text { LA). } \\
0.000 \mathrm{UI} ; \\
\text { o (nicotinic } \\
\text { acitracina } \\
\text { s.p. (q.s.p. } \\
\mathrm{Cu}, 10 \mathrm{~g} \text {; } \\
\text { ta. }\end{array}$ \\
\hline
\end{tabular}

cortes nobres (coxa, sobrecoxa, peito e pernas - coxa + sobrecoxa), das penas, da gordura abdominal e do peso de órgãos das aves aos 42 dias de idade.

$\mathrm{Na}$ determinação do rendimento de carcaça, foi considerado o peso da carcaça limpa e eviscerada (com cabeça e pés), em relação ao peso vivo em jejum.
A gordura abdominal foi considerada como tecido adiposo contido ao redor da cloaca, da Bursa de Fabricius e dos músculos abdominais adjacentes, conforme descrito por SMITH (1993).

Para os cortes nobres, peito com osso, coxas, sobrecoxas e pernas (coxa + sobrecoxa), procedeu- 
se à pesagem e ao cálculo dos rendimentos em relação ao peso da carcaça eviscerada e depenada.

As carcaças (com pés e cabeça) foram moídas em "cutter" comercial de 30 HP e 1775 rpm e, após homogeneização, foram retiradas amostras para posteriores análises laboratoriais. As amostras foram pré-secadas em estufa, com ventilação forçada $\mathrm{a}+55^{\circ} \mathrm{C}$, por 72 horas. Em seguida, realizou-se o prédesengorduramento, pelo método quente no extrator tipo "Soxhlet", durante quatro horas, devido ao alto teor de gordura das amostras. Após o prédesengorduramento, as amostras foram moídas, acondicionadas em vidros e armazenadas em geladeira para as análises subseqüentes. A água e a gordura, extraídas no preparo das amostras, foram consideradas para correção dos valores das análises obtidos.

Um grupo adicional de 24 aves com 22 dias de idade foi abatido para determinação da composição corporal das aves no início do experimento. As carcaças deste grupo foram processadas da mesma forma que as do experimento.

As análises bromatológicas (extrato etéreo, proteína e matéria seca) das carcaças dos frangos de corte foram realizadas no Laboratório de Nutrição Animal do Departamento de Zootecnia da UFV, de acordo com os métodos descritos por SILVA (1990).

As deposições de gordura e proteína nas carcaças foram calculadas comparando-se as composições das carcaças das aves do início (22 dias de idade) e do final (42 dias de idade) do período experimental.

As análises estatísticas das variáveis estudadas foram realizadas utilizando-se o programa SAEG (Sistema para Análises Estatísticas e Genéticas), desenvolvido na UNIVERSIDADE FEDERAL DE VIÇOSA - UFV (1982).

As estimativas de exigência de energia metabolizável para os frangos de corte no período de 22 a 42 dias de idade, mantidos em ambiente termoneutro, foram estabelecidas com base nos resultados de ganho de peso e conversão alimentar, por meio de modelos de regressão linear, quadrática e, ou, descontínuo "Linear Response Plateau" (LRP), conforme o melhor ajuste obtido para cada variável.

\section{Resultados e Discussão}

As médias de temperatura e umidade relativa do ar registradas durante o período experimental no interior das câmaras climáticas, assim como o Índice de Temperatura de Globo e Umidade (ITGU), são mostradas na Tabela 2.
Os resultados de desempenho, consumos de energia metabolizável e proteína bruta e deposições de gordura e proteína na carcaça dos frangos de corte, no período de 22 a 42 dias de idade, mantidos em ambiente termoneutro, são mostrados na Tabela 3 .

Verificou-se efeito $(\mathrm{P}<0,01)$ dos níveis de energia metabolizável (EM) da ração sobre o ganho de peso (GP), que aumentou de forma linear, no entanto, o modelo descontínuo "Linear Response Plateau" - LRP foi o que melhor se ajustou aos dados $(\mathrm{P}<0,01)$, estimando-se em 3232 kcal o nível de EM a partir do qual ocorreu um platô (Figura 1).

Resultados semelhantes foram obtidos por BERTECHINI et al. (1991a), que verificaram melhora linear no ganho de peso de frangos de corte machos mantidos em ambiente de termoneutralidade $\left(22,2^{\circ} \mathrm{C}\right)$, recebendo ração com três níveis de EM (2800, 3000 e $3200 \mathrm{kcal} / \mathrm{kg})$.

A conversão alimentar $(\mathrm{CA})$, à semelhança do que ocorreu para o GP, melhorou $(\mathrm{P}<0,01)$ de forma linear, em razão dos níveis de EM na ração. Todavia, em razão da distribuição dos dados, o melhor ajustamento foi obtido com o modelo "Linear Response Plateau" LRP, que apresentou menor soma dos quadrados dos desvios na opção em que se consideraram três pontos na reta $(3000,3075$ e $3150 \mathrm{kcal}$ de EM) e dois no platô (3225 e 3300 kcal de EM), estimando-se a exigência de EM das aves em 3210 kcal de EM (Figura 2).

Melhora no GP e na CA de frangos de corte, em razão do aumento do nível de EM da ração, também foi observada por diferentes autores (JACKSON et al., 1982; HOLSHEIMER e VEERKAMP; 1992, BENICIO, 1995; e LEESON et al., 1996).

Os níveis de EM de 3232 e 3224 kcal, que proporcionaram os melhores resultados de GP e CA,

Tabela 2 - Condições ambientais médias observadas nas câmaras climáticas para os frangos de corte mantidos em ambiente termoneutro, durante o período experimental

Table 2 - Average environment conditions observed in the climatic chambers for the broilers maintained under thermoneutral environment, during the experimental period

Temperatura do ar média $\left({ }^{\circ} \mathrm{C}\right)$

$23,2 \pm 0,74$

Average air temperature

Umidade relativa média $(\%)$

Average relative humity

Temperatura de globo negro média $\left({ }^{\circ} \mathrm{C}\right)$

$69 \pm 2,91$

Average black globe temperature

Índice de temperatura de globo e umidade (ITGU) 72+0,94 Black globe humidity index (BGHI) 


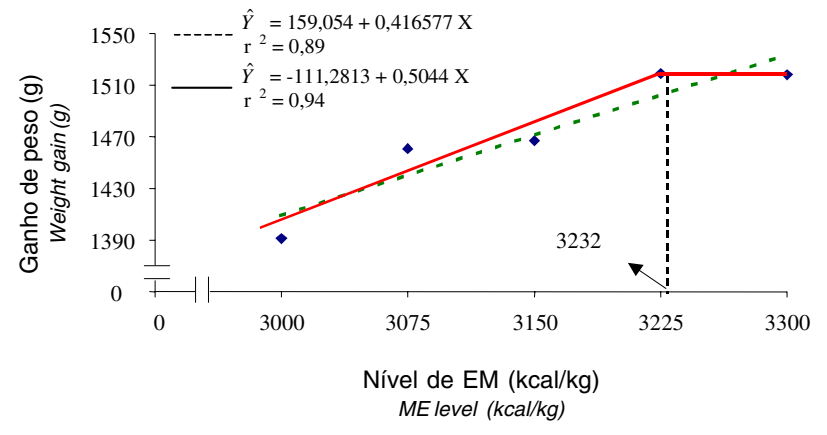

Figura 1 - Efeito do nível de EM da ração sobre o ganho de peso de frangos de corte mantidos em ambiente termoneutro.

Figure 1 - Effect of the dietary ME level on the weight gain of broilers mantained under thermoneutral environment.

estão coerentes com o recomendado $(3200 \mathrm{kcal}$ de EM) pelo NRC (1994), ficando, no entanto, acima daquele $(3100 \mathrm{kcal}$ de $\mathrm{EM})$ recomendado por ROSTAGNO et al. (1996).

O consumo de energia metabolizável (CEM) aumentou $(\mathrm{P}<0,01)$ de forma linear, em razão dos níveis de EM da ração, segundo a equação $\hat{\mathrm{Y}}=52,3242+2,7991 \mathrm{EM}\left(\mathrm{r}^{2}=0,99\right)$. O fato de se ter fornecido ração de forma controlada e níveis crescentes de EM justifica este resultado.

$\mathrm{O}$ aumento do CEM resultou em melhora $(\mathrm{P}<0,06)$ linear da deposição de proteína na carcaça, apesar de não ter ocorrido diferença no consumo de proteína entre os tratamentos. Estes resultados evidenciaram que ocorreu melhora gradativa na relação energia:proteína, que variou de 15,3 a 16,8, à medida que se aumentou o nível de EM da ração.

A maior eficiência ocorrida na utilização da proteína justifica a melhora no GP e na CA das aves, com a elevação dos níveis de EM da ração. Sabe-se que a proteína agrega maior quantidade de água por grama depositado, de forma que o aumento da sua deposição na carcaça proporciona maior ganho de peso, com melhoria na CA dos animais.

Com base nos resultados de CEM e deposição de proteína, pode-se inferir que ocorreu melhora na relação energia:proteína da ração, quando esta se elevou de 15,31 (no nível de $3000 \mathrm{kcal}$ ) para 16,45 (no nível de $3225 \mathrm{kcal}$ ).

Os níveis de EM da ração também influenciaram de forma linear crescente $(\mathrm{P}<0,01)$ a deposição de gordura na carcaça (DGC), segundo a equação $\hat{\mathrm{Y}}=-65,3789+0,07074 \mathrm{EM} \quad\left(\mathrm{r}^{2}=0,89\right) . \mathrm{O}$ aumento linear na DGC é explicado pelo aumento no CEM, o que está de acordo com MACARI et al. (1994), que

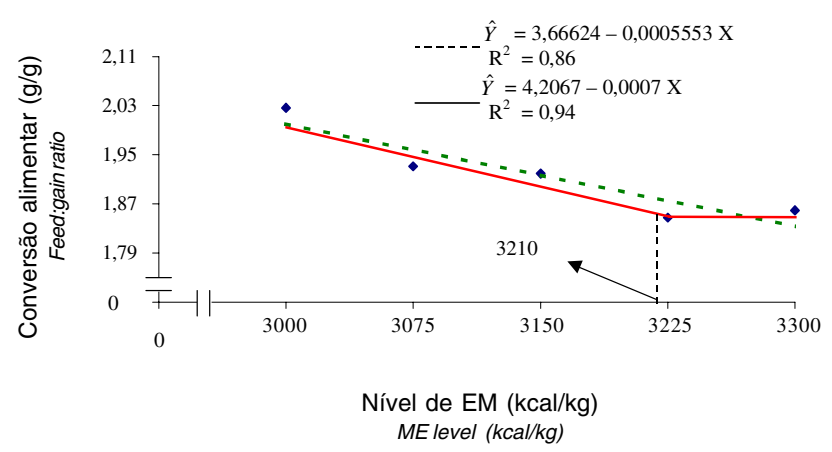

Figura 2 - Efeito do nível de EM da ração sobre a conversão alimentar de frangos de corte mantidos em ambiente termoneutro.

Figure 2 - Effect of the dietary ME level on the feed:gain of broilers maintained under thermoneutral environment.

relataram maior deposição de gordura nos frangos de corte recebendo rações com altos níveis de energia.

Embora a deposição de gordura na carcaça tenha aumentado de forma linear, constatou-se que, entre os níveis de 3000 e $3150 \mathrm{kcal}$ de EM, em que as relações energia:proteína ficaram abaixo de 16,45, definida como a mais ajustada, a deposição de gordura não variou acima de 3,3\%. No entanto, ao se comparar o valor médio de deposição de gordura, dos três menores níveis de energia, com o valor médio dos dois maiores, constatou-se variação de 9,9\%.

BERTECHINI et al. (1991b), avaliando os efeitos dos níveis de EM da ração, constataram aumento linear no teor de gordura (\%) da carcaça de frangos de corte, em razão de níveis mais altos de energia contidos na ração.

Os pesos absolutos ( $\mathrm{g}$ ) de todas as variáveis avaliadas, os rendimentos (\%) de carcaça, coxa, sobrecoxa, pernas e peito e o peso relativo da gordura abdominal (\%) e das penas de frangos de corte, recebendo rações com diferentes densidades energéticas, mantidos em ambiente termoneutro, são mostrados na Tabela 4.

Os pesos absolutos e o rendimento dos cortes não foram influenciados pelos níveis de energia estudados, com exceção do rendimento de carcaça, que variou $(\mathrm{P}<0,04)$ de forma quadrática, em razão dos níveis de EM. Entretanto, o modelo LRP foi o que melhor se ajustou aos dados, apresentando menor soma do quadrado dos desvios, na opção em que se consideraram dois pontos na reta $(3000$ e $3075 \mathrm{kcal}$ de EM) e três no platô $(3150,3225$ e $3300 \mathrm{kcal}$ de EM), estimando-se em $3117 \mathrm{kcal}$ o nível a partir do qual ocorreu um platô (Figura 3). Este resultado corrobora os encontrados por SKINNER et al. (1992), 
OLIVEIRA NETO et al.

Tabela 3 - Efeito do nível de energia metabolizável da ração sobre o desempenho e as deposições de proteína e gordura na carcaça de frangos de corte mantidos em ambiente termoneutro

Table 3 - Effect of dietary metabolizable energy level on the performance and protein and fat depositions in the carcass of broilers maintained under thermoneutral environment

\begin{tabular}{|c|c|c|c|c|c|c|}
\hline \multirow[t]{2}{*}{ Item } & \multicolumn{5}{|c|}{$\begin{array}{c}\text { Nível de energia metabolizável }(\mathrm{kcal} / \mathrm{kg}) \\
\text { Metabolizable energy level }(\mathrm{kcal} / \mathrm{kg})\end{array}$} & \multirow{2}{*}{$\begin{array}{l}\mathrm{CV} \\
(\%)\end{array}$} \\
\hline & 3000 & 3075 & 3150 & 3225 & 3300 & \\
\hline $\begin{array}{l}\text { Peso final }(\mathrm{g}) \\
\text { Final weight }\end{array}$ & 2145 & 2215 & 2221 & 2271 & 2267 & 1,64 \\
\hline $\begin{array}{l}\text { Ganho de peso }(\mathrm{g})^{1} \\
\text { Weight gain }\end{array}$ & 1391 & 1461 & 1467 & 1519 & 1518 & 2,41 \\
\hline $\begin{array}{l}\text { Consumo ração }(\mathrm{g}) \\
\text { Feed intake }\end{array}$ & 2818 & 2820 & 2813 & 2805 & 2823 & 0,34 \\
\hline $\begin{array}{l}\text { Conversão alimentar }{ }^{1} \\
\text { Feed: gain ratio }\end{array}$ & 2,03 & 1,93 & 1,92 & 1,85 & 1,86 & 2,37 \\
\hline $\begin{array}{l}\text { Consumo EM }(\mathrm{Kcal})^{1} \\
\text { ME intake }\end{array}$ & 8454 & 8670 & 8861 & 9047 & 9315 & 0,34 \\
\hline $\begin{array}{l}\text { Consumo de proteína }(\mathrm{g}) \\
\text { Protein intake }\end{array}$ & 552 & 553 & 551 & 550 & 553 & 0,34 \\
\hline $\begin{array}{l}\text { Relação energia: proteína } \\
\text { Protein:energyratio }\end{array}$ & 15,31 & 15,69 & 16,07 & 16,45 & 16,84 & \\
\hline \multicolumn{7}{|l|}{ Deposição na carcaça (g) } \\
\hline $\begin{array}{l}\text { Carcass deposition } \\
\text { Proteína } 2 \\
\text { Protein }\end{array}$ & 184 & 181 & 180 & 189 & 190 & 4,11 \\
\hline $\begin{array}{l}\text { Gordura } \\
\text { Fat }\end{array}$ & 150 & 149 & 154 & 162 & 170 & 8,43 \\
\hline
\end{tabular}

embora seja diferente dos de BERTECHINI et al. (1991a) e HOLSHEIMER e VEERKAMP (1992), que verificaram maiores rendimentos de carcaça dos frangos de corte aos 49 dias nos níveis mais altos de energia na ração.

Por outro lado, OLOMU e OFFIONG (1980) e BENICIO (1995) não observaram efeito dos níveis de energia da ração sobre o rendimento de carcaça.

Os pesos, absoluto e relativo, da gordura abdominal na carcaça não foram influenciados $(\mathrm{P}>0,05)$ pelo níveis de energia da ração. No entanto, de maneira similar à deposição de gordura na carcaça, foi constatado que as aves submetidas aos dois maiores níveis de EM apresentaram, em média, 12,23\% mais gordura abdominal na carcaça em relação às que receberam rações correspondentes aos três menores níveis de energia, cujos valores variaram somente $4,3 \%$ entre si.

De acordo com MACARI et al. (1994), frangos de corte recebendo rações com altos níveis de EM apresentaram maiores quantidades de gordura abdominal. Pode-se deduzir, com base nestes resultados, que, em condições de termoneutralidade, a deposição de gordura nas aves parece ocorrer de maneira proporcional entre a carcaça e a gordura abdominal.

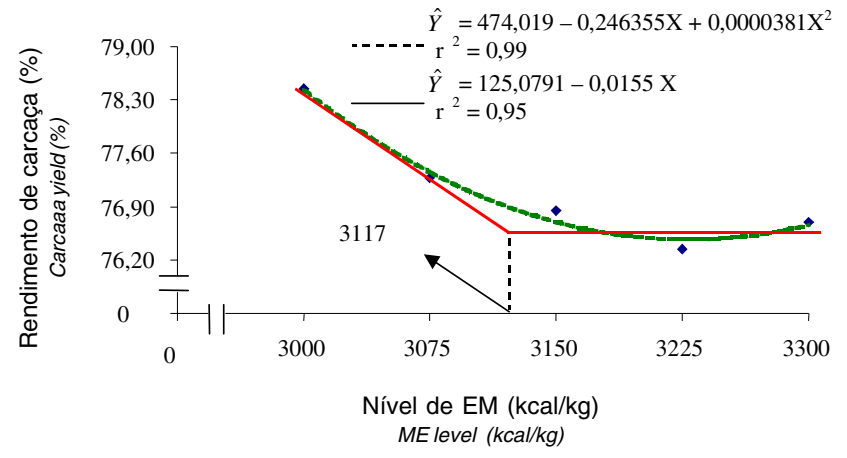

Figura 3 - Efeito do nível de EM da ração sobre o rendimento de carcaça de frangos de corte mantidos em ambiente termoneutro.

Figure 3 - Effect of the dietary ME level on the carcass yield of broilers maintained under thermoneutral environment.

Os pesos, absoluto ( $\mathrm{g}$ ) e relativo (\%), das penas de frangos de corte recebendo rações com diferentes níveis de EM, mantidos em ambiente termoneutro, são apresentados na Tabela 4. Observou-se que os pesos, absoluto e relativo, das penas não foram influenciados pelos níveis de EM avaliados, indicando 
1138 Rev. bras. zootec.

Tabela 4 - Efeito do nível de energia metabolizável da ração (kcal EM/kg de ração) sobre o peso absoluto, rendimento e peso relativo de carcaça, corte nobres, gordura abdominal e penas dos frangos de corte mantidos em ambiente termoneutro

Table 4 - Effect of the dietary metabolizable energy level ( $\mathrm{kcal}$ of $\mathrm{ME} / \mathrm{kg}$ of diet) on the absolute weight, carcass yield and relative weight, parts yield, abdominal fat and feathers of broilers maintained under thermoneutral environment

\begin{tabular}{|c|c|c|c|c|c|c|}
\hline \multirow[t]{2}{*}{ Item } & \multicolumn{5}{|c|}{$\begin{array}{c}\text { Nível de energia metabolizável }(\mathrm{kcal} / \mathrm{kg}) \\
\text { Metabolizable energy level }(\mathrm{kcal} / \mathrm{kg})\end{array}$} & \multirow{2}{*}{$\begin{array}{l}\mathrm{CV} \\
(\%)\end{array}$} \\
\hline & 3000 & 3075 & 3150 & 3225 & 3300 & \\
\hline & \multicolumn{6}{|c|}{$\begin{array}{l}\text { Peso absoluto }(\mathrm{g}) \\
\text { Absolute weight }\end{array}$} \\
\hline $\begin{array}{l}\text { Peso vivo jejum (g) } \\
\text { Fast live weight }\end{array}$ & 2082 & 2145 & 2148 & 2187 & 2181 & 1,98 \\
\hline $\begin{array}{l}\text { Carcaça } \\
\text { Carcass }\end{array}$ & 1632 & 1667 & 1656 & 1691 & 1664 & 1,81 \\
\hline $\begin{array}{l}\text { Coxa } \\
\text { Drumstick }\end{array}$ & 223 & 227 & 226 & 228 & 224 & 3,28 \\
\hline $\begin{array}{l}\text { Sobrecoxa } \\
\text { Thigh }\end{array}$ & 231 & 230 & 229 & 231 & 225 & 3,90 \\
\hline $\begin{array}{l}\text { Pernas } \\
\text { Legs }\end{array}$ & 454 & 457 & 455 & 459 & 449 & 2,75 \\
\hline $\begin{array}{l}\text { Peito } \\
\text { Breast }\end{array}$ & 448 & 441 & 441 & 451 & 439 & 2,82 \\
\hline $\begin{array}{l}\text { Gordura abdominal } \\
\text { Adbominal fat }\end{array}$ & 26,8 & 25,9 & 25,1 & 27,9 & 28,0 & 15,57 \\
\hline $\begin{array}{l}\text { Penas } \\
\text { Feathers }\end{array}$ & 99,8 & 105,0 & 101,5 & 100,0 & 99,8 & 10,33 \\
\hline & \multicolumn{6}{|c|}{$\begin{array}{l}\text { Rendimento }(\%) \\
\text { Yield }\end{array}$} \\
\hline $\begin{array}{l}\text { Carcaça }^{1} \\
\text { Carcass }\end{array}$ & 78,44 & 77,28 & 76,84 & 76,34 & 76,70 & 1,14 \\
\hline $\begin{array}{l}\text { Coxa } \\
\text { Drumstick }\end{array}$ & 13,41 & 13,60 & 13,68 & 13,49 & 13,44 & 2,85 \\
\hline $\begin{array}{l}\text { Sobrecoxa } \\
\text { Thigh }\end{array}$ & 13,91 & 13,79 & 13,83 & 13,66 & 13,52 & 3,59 \\
\hline $\begin{array}{l}\text { Pernas } \\
\text { Legs }\end{array}$ & 27,32 & 27,40 & 27,51 & 27,16 & 26,97 & 2,21 \\
\hline $\begin{array}{l}\text { Peito } \\
\text { Breast }\end{array}$ & 26,96 & 26,44 & 26,63 & 26,65 & 26,36 & 2,32 \\
\hline Dreast & \multicolumn{6}{|c|}{$\begin{array}{l}\text { Peso relativo (\%) } \\
\text { Relative weight }\end{array}$} \\
\hline $\begin{array}{l}\text { Gordura abdominal } \\
\text { Abdominal fat }\end{array}$ & 1,60 & 1,56 & 1,49 & 1,65 & 1,67 & 15,77 \\
\hline Penas & 6,02 & 6,31 & 6,14 & 5,92 & 6,01 & 10,24 \\
\hline
\end{tabular}

1 Efeito quadrático $(P<0,05)$.

1 Quadratic effect $(P<.05)$.

que o peso de penas variou de acordo com o crescimento corporal das aves.

Os pesos, absoluto $(\mathrm{g})$ e relativo (\%) dos órgãos (coração, fígado, moela, proventrículo, pulmões e intestinos), de frangos de corte machos no período de 22 a 42 dias de idade, alimentados com diferentes níveis de EM, são apresentados na Tabela 5.

Observou-se que os pesos, absoluto e relativo, de coração, fígado, moela, proventrículo, pulmões e intestino não foram influenciados pelos níveis de ener- gia da ração, embora o CEM tenha variado em $9,1 \%$ entre os tratamentos. OLOMU e OFFIONG (1980), também, não encontraram efeito da energia sobre o peso relativo de coração, fígado e moela de frangos de corte, concluindo que o rendimento da carcaça e dos órgãos comestíveis é pouco influenciado pelos níveis de energia da ração.

Os resultados encontrados estão de acordo com os observados em estudos com suínos, por OLIVEIRA et al. (1997), os quais concluíram que as 
OLIVEIRA NETO et al.

Tabela 5 - Efeito do nível de energia metabolizável da ração sobre os pesos absoluto e relativo dos órgãos de frangos de corte, aos 42 dias de idade, mantidos em ambiente termoneutro

Table 5 - Effect of the dietary metabolizable energy level on the absolute and relative weights of organs of broilers, at 42 days of age, maintained under thermoneutral environment

\begin{tabular}{|c|c|c|c|c|c|c|}
\hline \multirow[t]{2}{*}{ Item } & \multicolumn{5}{|c|}{$\begin{array}{c}\text { Nível de energia metabolizável (kcal/kg) } \\
\text { Metabolizable energy level }(\text { kcal/kg) }\end{array}$} & \multirow{2}{*}{$\begin{array}{l}\mathrm{CV} \\
(\%)\end{array}$} \\
\hline & 3000 & 3075 & 3150 & 3225 & 3300 & \\
\hline & \multicolumn{6}{|c|}{$\begin{array}{l}\text { Peso absoluto }(\mathrm{g}) \\
\text { Absolute weight }\end{array}$} \\
\hline $\begin{array}{l}\text { Coração } \\
\text { Heart }\end{array}$ & 11,5 & 12,0 & 12,9 & 12,1 & 11,5 & 11,04 \\
\hline $\begin{array}{l}\text { Fígado } \\
\text { Liver }\end{array}$ & 42,6 & 45,0 & 42,2 & 44,7 & 42,2 & 6,86 \\
\hline $\begin{array}{l}\text { Moela } \\
\text { Gizzard }\end{array}$ & 31,2 & 32,7 & 33,1 & 31,6 & 32,4 & 7,35 \\
\hline $\begin{array}{l}\text { Proventrículo } \\
\text { Proventriculus }\end{array}$ & 7,7 & 8,1 & 7,8 & 9,0 & 7,6 & 9,04 \\
\hline $\begin{array}{l}\text { Pulmões } \\
\text { Lungs }\end{array}$ & 12,5 & 12,6 & & 12,7 & 11,3 & 8,13 \\
\hline \multirow{2}{*}{$\begin{array}{l}\text { Intestino } \\
\text { Intestine }\end{array}$} & 62,0 & 65,1 & 64,7 & 66,7 & 64,6 & 8,77 \\
\hline & \multicolumn{6}{|c|}{$\begin{array}{l}\text { Peso relativo }(\%) \\
\text { Relative weight }\end{array}$} \\
\hline $\begin{array}{l}\text { Coração } \\
\text { Heart }\end{array}$ & 0,69 & 0,72 & 0,78 & 0,72 & 0,69 & 10,71 \\
\hline $\begin{array}{l}\text { Fígado } \\
\text { Liver }\end{array}$ & 2,57 & 2,70 & 2,55 & 2,65 & 2,53 & 5,99 \\
\hline $\begin{array}{l}\text { Moela } \\
\text { Gizzard }\end{array}$ & 1,88 & 1,96 & 2,00 & 1,87 & 1,95 & 8,55 \\
\hline $\begin{array}{l}\text { Proventrículo } \\
\text { Proventriculus }\end{array}$ & 0,47 & 0,49 & 0,47 & 0,54 & 0,46 & 9,33 \\
\hline $\begin{array}{l}\text { Pulmões } \\
\text { Lungs }\end{array}$ & 0,75 & 0,75 & 0,77 & 0,75 & 0,68 & 8,65 \\
\hline $\begin{array}{l}\text { Intestino } \\
\text { Intestine }\end{array}$ & 3,74 & 3,91 & 3,90 & 3,94 & 3,88 & 9,19 \\
\hline
\end{tabular}

Tabela 6 - Efeito do nível de energia metabolizável da ração sobre a concentração sérica de triiodotironina $\left(\mathrm{T}_{3}\right)$ livre dos frangos de corte, aos 42 dias de idade, mantidos em ambiente termoneutro

Table 6 - Effect of the dietary metabolizable energy level on the free triiodotironine $\left(T_{3}\right)$ serum concentration of the broilers, at 42 days of age, maintained under thermoneutral environment

\begin{tabular}{|c|c|c|c|c|c|c|}
\hline \multirow[t]{2}{*}{ Item } & \multicolumn{5}{|c|}{$\begin{array}{l}\text { Nível de energia metabolizável }(\mathrm{kcal} / \mathrm{kg}) \\
\text { Metabolizable energy level }(\mathrm{kcal} / \mathrm{kg})\end{array}$} & \multirow{2}{*}{$\begin{array}{l}\mathrm{CV} \\
(\%)\end{array}$} \\
\hline & 3000 & 3075 & 3150 & 3225 & 3300 & \\
\hline & \multicolumn{6}{|c|}{$\begin{array}{c}\text { Parâmetro hormonal }(\mathrm{pg} / \mathrm{mL}) \\
\text { Hormonal parameter }\end{array}$} \\
\hline $\begin{array}{l}\mathrm{T}_{3} \text { livre } \\
\text { Free } T_{3}\end{array}$ & 5,57 & 5,24 & 6,48 & 6,17 & 6,14 & 24,49 \\
\hline
\end{tabular}


1140 Rev. bras. zootec.

variações nos pesos dos órgãos desses animais estão mais relacionadas ao seu desenvolvimento corporal que aos níveis de energia utilizados nas rações.

Os resultados da concentração sérica do hormônio triiodotironina $\left(\mathrm{T}_{3}\right)$ livre, de frangos de corte machos Hubbard, aos 42 dias de idade, mantidos em ambiente termoneutro, recebendo rações com diferentes níveis de EM, encontram-se na Tabela 6.

Verificou-se que os níveis de EM não influenciaram a concentração de $\mathrm{T}_{3}$ livre no soro sangüíneo das aves. Estes resultados diferem dos obtidos com aves na fase inicial, por ZANUSSO (1998), e suínos, por OLIVEIRA et al. (1997) e FERREIRA (1998), os quais constataram que o aumento do nível de energia da ração elevou a concentração de $\mathrm{T}_{3}$ livre no soro sangüíneo dos animais em condição de conforto.

\section{Conclusões}

O nível de $3232 \mathrm{kcal}$ de EM, correspondente à relação energia:proteína calculada de 16,49 , proporcionou os melhores resultados de desempenho e deposição de proteína na carcaça de frangos de corte mantidos em ambiente termoneutro.

\section{Referências Bibliográficas}

BENICIO, L.A.S. Estudo da influência de linhagens e de níveis nutricionais sobre o desempenho, rendimento de carcaça e avaliação econômica em frangos de corte. Viçosa, MG: UFV, 1995. 159p. Tese (Doutorado em Zootecnia) Universidade Federal de Viçosa, 1995.

BERTECHINI, A.G., ROSTAGNO, H.S., SILVA, M.A. et al. 1991a. Efeitos da temperatura ambiente e nível de energia da ração sobre o desempenho e a carcaça de frangos de corte. R. Soc. Bras. Zootec., 20:218-228.

BERTECHINI, A.G., ROSTAGNO, H.S., FONSECA, J.B. et al. 1991b. Efeitos de forma física e nível de energia da ração sobre o desempenho e a carcaça de frangos de corte. R. Soc. Bras. Zootec., 20:229-240.

COFFEY, M.T., SEERLEY, R.W., FUNDERBURKE, D.W. et al. 1982. Effect of heat increment and level of dietary energy and environment temperature on the performance of growingfinishing swine. J. Anim. Sci., 54:95-105.

CURTIS, S.E. 1983. Environmental management in animal agriculture, 2.ed. Ames, Iowa: Iowa State Universty. 407p.

FERREIRA, R.A. Niveis de energia digestível para leitoas dos 15 aos $30 \mathrm{~kg}$ mantidas em ambiente de frio $\left(15^{\circ} \mathrm{C}\right)$. Viçosa, MG: UFV, 1998. 59p. Dissertação (Mestrado em Zootecnia) Universidade Federal de Viçosa, 1998.
GOMES, P.C., ALBINO, L.F.T., SILVA, M.A. 1996. Criação de frangos de corte. Viçosa, MG:UFV. 16p. (Informe técnico, 78).

HOLSHEIMER, J.P., VEERKAMP, C.H. 1992. Effect of dietary, protein, and lysine content on performance and yields of two strains of male broiler chicks. Poult. Sci., 71:872-879.

JACKSON, S., SUMMERS, J.D., LEESON, S. 1982. Effect of dietary protein and energy on broiler carcass composition and efficiency of nutrient utilization. Poult. Sci., 61:22242231.

LEESON, S., CASTON, L., SUMMERS, J.D. 1996. Broiler response to diet energy. Poult. Sci., 75:529-535.

MACARI, M., FURLAN, L.M., GONZALES, E. 1994. Fisiologia aviária aplicada a frangos de corte. Jaboticabal: FUNEP/UNESP. 296p.

NATIONAL RESEARCH COUNCIL - NRC. 1994. Nutrients requirements of poultry. 9.ed. Washington, D.C.: National Academic. $155 \mathrm{p}$.

OLIVEIRA, R.F.M., DONZELE, J.L., FREITAS, R.T.F. et al. 1997. Níveis de energia digestível para leitões dos 15 aos 30 $\mathrm{kg}$ de peso mantidos em ambiente de conforto térmico. R. Bras. Zootec., 26:539-547.

OLOMU, J.M., OFFIONG, S.A. 1980. The effects of different protein and energy levels and time of change form starter to finisher ration on the performance of broiler chicken in the tropics. Poult. Sci., 59:828-835.

ROSTAGNO, H.S., BARBARINO JR., P., BARBOSA, W.A. Exigências nutricionais das aves determinadas no Brasil. In: SIMPOSIO INTERNACIONAL SOBRE EXIGÊNCIAS NUTRICIONAIS DE AVES E SUÍNOS, 1996, Viçosa, MG:UFV. Anais... Viçosa, p.369, 1996.

SILVA, D.J. 1990. Análise de alimentos: métodos químicos e biológicos. Viçosa, MG: UFV. 166p.

SKINNER, J.T., WALDROUP, A.L., WALDROUP, P.W. 1992. Effects of protein and amino acid level fed to forty-two days on response of broilers to protein and amino acid levels fed forty-two to forty-nine days of age. Poult. Sci., 71:1364-1373.

SMITH, M.O. 1993. Parts yield of broilers reared under cycling high temperatures. Poult. Sci., 72:1146-1150.

UNIVERSIDADE FEDERAL DE VIÇOSA - UFV. 1982. Manual de utilização do programa SAEG (Sistema para Análises Estatísticas e Genéticas). Viçosa - MG. 59p.

ZANUSSO, J.T. Níveis de energia metabolizável para frangos de corte de 1 a 21 dias de idade mantidos em ambiente de conforto térmico. Viçosa, MG: UFV, 1998. 64p. Dissertação (Mestrado em Zootecnia) - Universidade Federal de Viçosa, 1998.

Recebido em: 17/06/1999

Aceito em: 17/09/1999 